\title{
Simulation of Water Vapor Adsorption in a Fixed-bed Column with Silica Gel Material for Thermal Energy Storage Applications
}

\author{
Ye Carrier ${ }^{1}$, Curtis Strong ${ }^{1}$ and F. Handan Tezel ${ }^{1}$ \\ ${ }^{1}$ Department of Chemical and Biological Engineering, University of Ottawa \\ 161 Louis-Pasteur, Ottawa, Ontario, Canada, K1N 6N5 \\ yhua2@uottawa.ca; cstro043@uottawa.ca; handan.tezel@uottawa.ca
}

\section{Extended Abstract}

In order to reduce the environmental impact of fossil fuels and transition to a low-carbon economy, researchers around the world have been investing heavily in the development of renewable energy technologies. However, the renewable energy sources (e.g. wind power and solar energy) have the major constraint of intermittency and lack of consistency. Therefore, energy storage technologies play an important role in balancing the misalignment between the energy supply and demand, and creating a more flexible and reliable energy system [1].

Water vapor adsorption in porous materials in a fixed bed column can be used in the thermal energy storage (TES) systems for space heating applications. Various adsorbent materials have been tested and evaluated for their thermal energy storage abilities by our research group [2]-[6]. Silica gel has proven to be one of the better adsorbents with high energy storage density using low regeneration temperatures [5]. To gain a better understanding of this exothermic adsorption process, a mathematical model has been developed in this study, to simulate the water vapor adsorption process of silica gel material from humid air. The model included the mass and energy balances with equations to take into account the adsorption isotherms, the pressure-drop in the system, the heat of adsorption released during the process and the heat loss to the surroundings. The validated model can be used to optimize the TES system design and predict the TES system's performance under operating conditions that we are not able to create in our laboratories.

\section{References}

[1] J. Xu, R. Z. Wang, and Y. Li, “A review of available technologies for seasonal thermal energy storage," Sol. Energy, vol. 103, pp. 610-638, 2014.

[2] D. Dicaire and F. H. Tezel, "Use of adsorbents for thermal energy storage of solar or excess heat: improvement of energy density,” Int. J. Energy Res., vol. 37, no. 9, pp. 1059-1068, Jul. 2013.

[3] D. Dicaire and F. H. Tezel, "Regeneration and efficiency characterization of hybrid adsorbent for thermal energy storage of excess and solar heat," Renew. Energy, vol. 36, no. 3, pp. 986-992, 2011.

[4] Y. Hua, B. Ugur, and F. Handan Tezel, "Adsorbent screening for thermal energy storage application," Sol. Energy Mater. Sol. Cells, vol. 196, no. December 2018, pp. 119-123, 2019.

[5] Y. Hua, A. Godin, and F. H. Tezel, "Water Vapor Adsorption in Silica Gel For Thermal Energy Storage Application," Adv. Mater. Lett., vol. 10, no. 2, pp. 124-127, Feb. 2019.

[6] D. A. Bardy, C. A. Cruickshank, F. H. Tezel, Y. H. Carrier, and B. Wong, "An experimental investigation of fixed and fluidized beds as adsorbers in compact thermal energy storage systems," J. Energy Storage, vol. 31, no. June, p. $101648,2020$. 